\title{
VA FitHeart, a Mobile App for Cardiac Rehabilitation: Usability Study
}

Alexis L Beatty ${ }^{1,2}$, MAS, MD; Sara L Magnusson ${ }^{1,2}$, BA; John C Fortney ${ }^{1,3}$, PhD; George G Sayre ${ }^{1}$, MA, PsyD; Mary A Whooley ${ }^{4,5,6}, \mathrm{MD}$

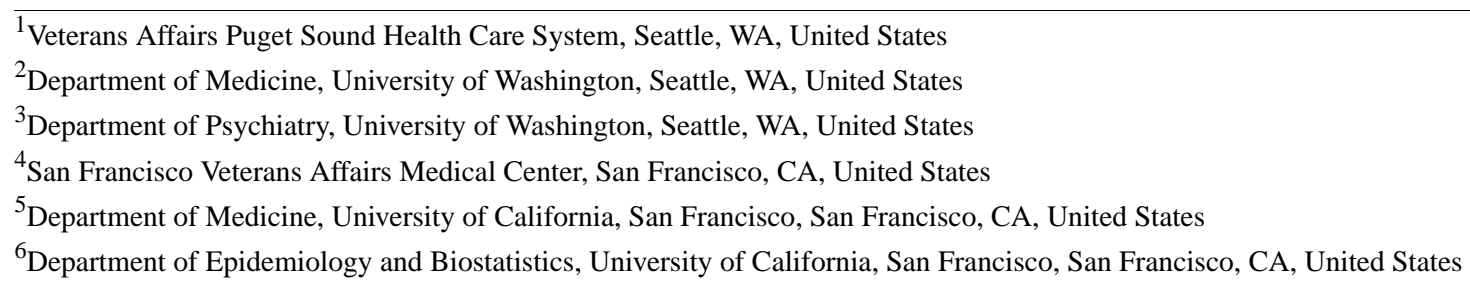

Corresponding Author:

Alexis L Beatty, MAS, MD

Veterans Affairs Puget Sound Health Care System

1600 S Columbian Way

Seattle, WA,

United States

Phone: 12067642008

Email: beattya@uw.edu

\section{Abstract}

Background: Cardiac rehabilitation (CR) improves outcomes for patients with ischemic heart disease or heart failure but is underused. New strategies to improve access to and engagement in CR are needed. There is considerable interest in technology-facilitated home CR. However, little is known about patient acceptance and use of mobile technology for CR.

Objective: The aim of this study was to develop a mobile app for technology-facilitated home CR and seek to determine its usability.

Methods: We recruited patients eligible for CR who had access to a mobile phone, tablet, or computer with Internet access. The mobile app includes physical activity goal setting, logs for tracking physical activity and health metrics (eg, weight, blood pressure, and mood), health education, reminders, and feedback. Study staff demonstrated the mobile app to participants in person and then observed participants completing prespecified tasks with the mobile app. Participants completed the System Usability Scale (SUS, 0-100), rated likelihood to use the mobile app (0-100), questionnaires on mobile app use, and participated in a semistructured interview. The Unified Theory of Acceptance and Use of Technology and the Theory of Planned Behavior informed the analysis. On the basis of participant feedback, we made iterative revisions to the mobile app between users.

Results: We conducted usability testing in 13 participants. The first version of the mobile app was used by the first 5 participants, and revised versions were used by the final 8 participants. From the first version to revised versions, task completion success rate improved from $44 \%$ (11/25 tasks) to $78 \%$ (31/40 tasks; $P=.05)$, SUS improved from 54 to 76 ( $P=.04$; scale 0 -100, with 100 being the best usability), and self-reported likelihood of use remained high at 76 and $87(P=.30$; scale $0-100$, with 100 being the highest likelihood). In interviews, patients expressed interest in tracking health measures ("I think it'll be good to track my exercise and to see what I'm doing"), a desire for introductory training ("Initially, training with a technical person, instead of me relying on myself"), and an expectation for sharing data with providers ("It would also be helpful to share with my doctor, it just being a matter of clicking a button and sharing it with my doctor").

Conclusions: With participant feedback and iterative revisions, we significantly improved the usability of a mobile app for CR. Patient expectations for using a mobile app for CR include tracking health metrics, introductory training, and sharing data with providers. Iterative mixed-method evaluation may be useful for improving the usability of health technology.

(JMIR Hum Factors 2018;5(1):e3) doi: 10.2196/humanfactors.8017 


\section{KEYWORDS}

cardiac rehabilitation; mobile applications; exercise therapy; exercise; rehabilitation research; telemedicine; habits; qualitative research

\section{Introduction}

Cardiac rehabilitation (CR) is an evidence-based program of exercise training, risk factor management, education, and counseling that improves outcomes for patients with heart disease [1-4]. However, CR is dramatically underused, with less than $20 \%$ of eligible patients participating [5-7] . Many barriers limit participation, including expectations for attending facility-based supervised exercise sessions three times per week for 12 weeks, transportation difficulties, competing demands related to work or family, lack of social support, and cost [8-10]. Home-based CR programs are similar in efficacy and safety to facility-based programs but have not been widely adopted in the United States $[11,12]$. New strategies are needed to promote participation in home-based CR [13,14].

Technology has the potential to facilitate health interventions and motivate patients to improve health behaviors, including for the secondary prevention of cardiovascular disease [15-19]. It is known that interventions with a theoretical basis are more effective [20], but most technology solutions have not been created around evidence-based practices or health behavior theory [18,21-23]. The Theory of Planned Behavior (TPB) [24] has been successfully applied to CR in both facility- and home-based settings [25,26]. The TPB states that the most important determinant of behavior is the intention to perform the behavior. Behavioral intention is influenced by constructs of attitudes, subjective norms, and perceived behavioral control. An extension of the TPB has been developed to explain behavior specific to technology use, called the Unified Theory of Acceptance and Use of Technology (UTAUT) [27] and its extension for consumer use of technology (UTAUT2) [28]. This theory contends that constructs of performance expectancy, effort expectancy, social influence, facilitating conditions, hedonic motivation, price value, and habit influence behavioral intention, which is the strongest predictor of technology use.

Using the TPB and UTAUT2, we developed a theory-based mobile app for technology-facilitated home CR. We tested the mobile app in patients eligible for CR, obtained feedback, and iteratively made revisions to the mobile app to improve its usability. Additionally, we interviewed participants about physical activity, CR, and mobile app use to better understand how to implement technology-facilitated home CR. The aims of this study were to determine the usability of the VA FitHeart mobile app and to analyze factors contributing to its use.

\section{Methods}

\section{Overview}

We conducted an observational study of Veteran use of a mobile Web app, VA FitHeart. The mobile app was designed to be used as a tool for home CR and includes physical activity goal setting, logs for physical activity and health measures (eg, blood pressure, pulse, weight, glucose, cholesterol, and mood), health education, reminders, and feedback (Figure 1). The mobile app was developed by the Department of Veterans Affairs (VA), and testing was conducted on versions of the mobile app hosted on preproduction testing servers. VA FitHeart was designed with input from subject matter experts (including the authors), patients eligible for $\mathrm{CR}$, user experience designers, and mobile app developers. VA FitHeart underwent iterative revision based on review from VA mobile compliance bodies, including human factors, section 508 compliance, patient safety, data and terminology standardization, branding, and data security. During the course of this study, VA FitHeart underwent iterative user interface revisions based on participant feedback on usability. Because the app was hosted in a testing environment, there were occasional server downtimes when the app was not accessible for testing.

\section{Participants}

Veterans attending the outpatient cardiology clinic at the VA Puget Sound Health Care System in Seattle, WA were screened for enrollment in the study. Eligibility criteria included the ability to speak English, age $\geq 21$, and eligibility for CR, defined as myocardial infarction, percutaneous coronary intervention, or cardiac surgery in the past year or having chronic stable angina or heart failure. Participants were excluded if they were not eligible for CR. Participants meeting inclusion criteria were asked to participate in additional screening to participate in a study about a mobile app for CR. Participants were excluded if they did not have access to a mobile phone, tablet, or computer with Internet access. This study was reviewed and approved by the institutional review board at the VA Puget Sound Health Care System. All participants provided written, informed consent.

\section{Usability Testing}

Study staff demonstrated the mobile app to participants in person and asked participants to complete prespecified tasks with the mobile app while study staff observed the participants. Tasks demonstrated by study staff included setting a physical activity goal, making a physical activity entry, viewing a fitness graph, making a weight entry, and viewing an educational module. After the conclusion of the demonstration, participants were asked to complete the demonstrated tasks independently. Study staff recorded task completion success if the participant was able to successfully complete the task.

\section{Questionnaires}

Following testing, participants completed questionnaires using REDCap electronic data capture tools hosted at the VA [29], including rating their likelihood to use the mobile app from 0 (low) to 100 (high). Participants completed the System Usability Scale (SUS) [30], with scoring from 0 to 100, with ratings of greater than 70 generally considered to demonstrate acceptable usability [31]. In addition, participants rated factors influencing mobile app use related to constructs from UTAUT2, including performance expectancy, social influence, facilitating conditions, 
habit, hedonic motivation, price value, and behavioral intention (scale 0-100; Multimedia Appendix 1) [28]. Effort expectancy was operationalized as response to the SUS.

\section{Interviews}

We conducted two separate semistructured interviews with Veterans enrolled in the study. The first interview was conducted before usability testing and was centered on physical activity and the use of technology. The second interview was conducted before usability testing, asking specific questions about the functionality of the mobile app. All interviews took place in person at the VA Puget Sound Health Care System in Seattle, WA in a private office. Both interviews had semistructured interview guides that included open-ended questions and prompts for elicitation of additional detail (Multimedia Appendix 2). Interviews were conducted by two trained study staff members, audiorecorded, and transcribed word for word.

Figure 1. Screenshots of VA FitHeart, a mobile app for cardiac rehabilitation.

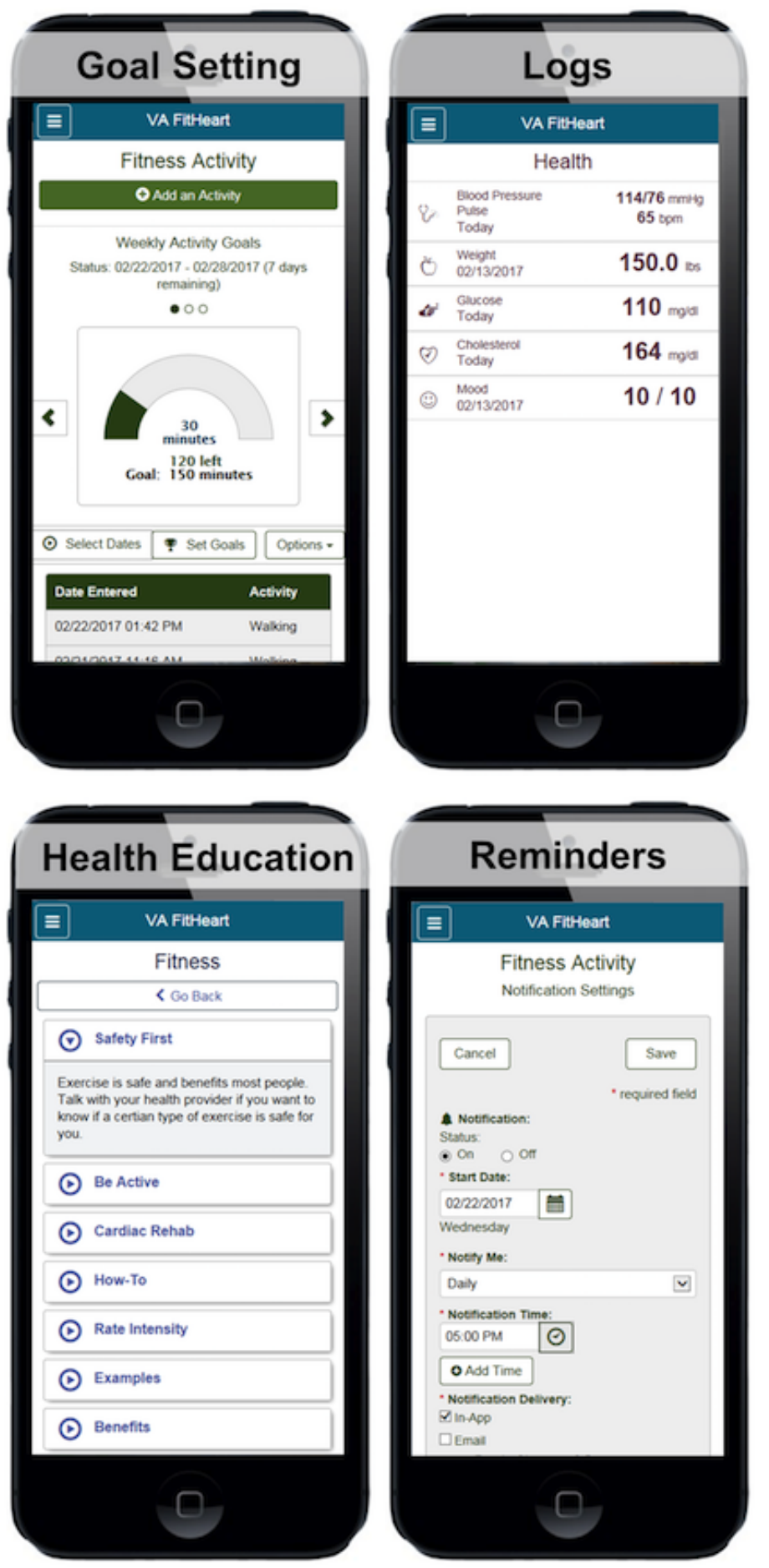




\section{Analysis}

Descriptive statistics of range and mean were used for quantitative questionnaire responses. To compare responses before and after, we performed a two-tailed $t$ test. Qualitative interviews were transcribed and coded using Atlas.ti (Atlas.ti $\mathrm{GmbH}$ ) version 7.2. Two researchers (ALB and SLM) coded interviews; we performed inductive and deductive content analysis [32]. We used a priori categories from the constructs of the UTAUT for consumer applications (performance expectancy, effort expectancy, social influence, facilitating conditions, habit, hedonic motivation, and price value) and the TPB (attitudes, subjective norms, and perceived behavioral control). In addition, we generated additional codes that emerged naturally based on participant responses. Both researchers wrote analytic memos to document observations and participated in intermittent meetings to discuss emergent themes, add or collapse codes, and reach consensus on coding disagreements. The research team conducted a thematic analysis to assess patterns of experiences and opinions across themes and reached agreement of interpretation. Analysis was conducted concurrently with participant enrollment. We continued enrollment of new participants until we had achieved acceptable usability and stakeholders believed that sufficient data had been collected to make the decision to not make additional revisions. The results of the study are reported in accordance with the Consolidated Standards of Reporting Trials of Electronic and Mobile HEalth Applications and onLine TeleHealth checklist [33].

Figure 2. Task completion success and patient-reported usability and likelihood of using the mobile app on initial and revised versions of the mobile app. Task completion success was the percentage of tasks successfully completed. Usability was score on the System Usability Scale (scale 0-100, with 100 being the best usability). Likely to use app was self-rated likelihood of use (scale $0-100$, with 100 being the highest likelihood). $P$ values represent comparisons between the initial version and revised versions.

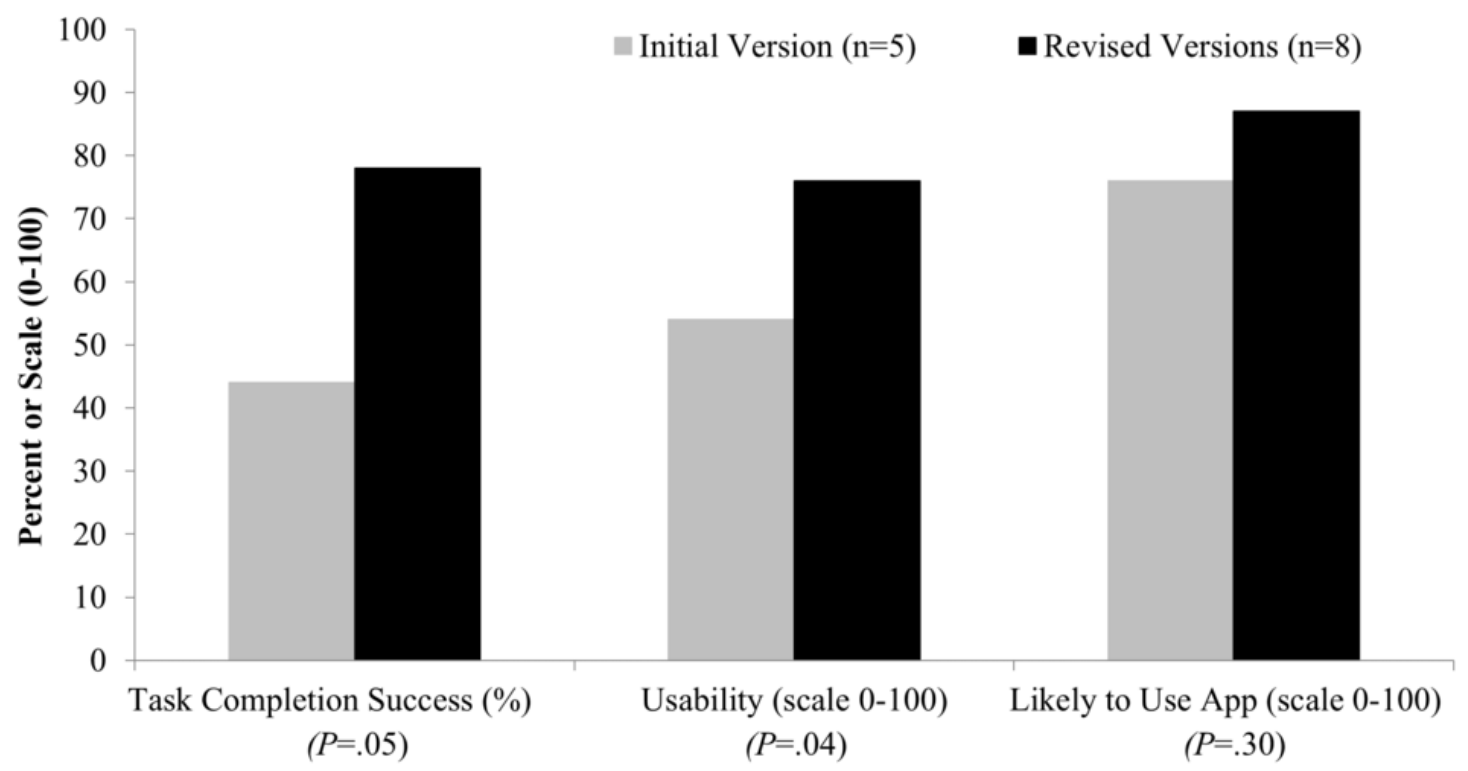

http://humanfactors.jmir.org/2018/1/e3/ (page number not for citation purposes)

\section{Participant Characteristics}

From January 27, 2016 to October 24, 2016, we enrolled 15 participants in usability testing (Multimedia Appendix 3). Participants ranged in age from 43 to 75 years (mean 63 years). There were 14 males and 1 female, and 13 participants identified race as white $(87 \%)$. Primary diagnoses included coronary artery bypass surgery $(2 / 15,13 \%)$, percutaneous coronary intervention $(3 / 15,20 \%)$, chronic stable angina $(5 / 15,33 \%)$, and stable heart failure $(6 / 15,40 \%)$.

\section{Usability Testing}

The first version of the mobile app was used by the first 5 participants, and revised versions were used by 8 participants. Two participants were unable to complete testing because of technical difficulties with accessing the servers in the preproduction testing environment during server downtimes. From the first version to revised versions, task completion success rate improved from $44 \%$ (11/25 tasks) to $78 \%$ (31/40 tasks; $P=.05)$, SUS improved from 54 to $76(P=.04$; scale 0 to 100 , with 100 being the best usability), and rated likelihood of using the mobile app remained high at 76 and $87(P=.30$; scale 0 to 100 , with 100 being the highest likelihood; Figure 2). We found that revised versions of the mobile app significantly improved constructs from UTAUT2, including effort expectancy, habit, and hedonic motivation (Figure 3).

\section{Results}


Figure 3. Patient-reported factors influencing mobile app use on initial and revised versions of the mobile app. Items were rated on a scale of 0 to 100 , with 100 being the best rating. $* P<.05$ for comparison between versions.

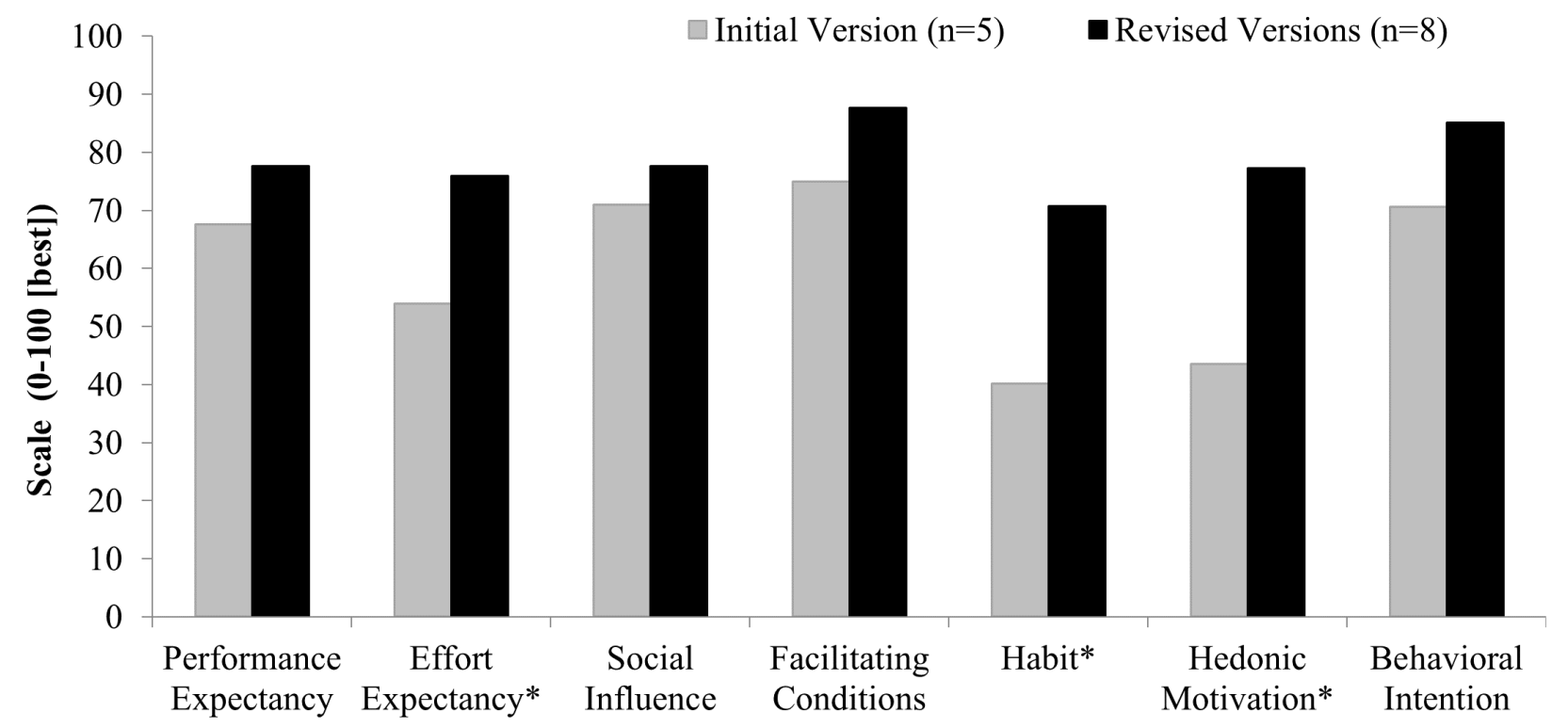

\section{Mobile Technology Use}

Emergent themes about mobile technology use were categorized by UTAUT2 construct (Multimedia Appendix 4).

\section{Performance Expectancy}

Many participants expect that VA FitHeart would be beneficial.

I think that the idea of an app that records all of the information that this app is doing will be very valuable. Actually somewhat of a motivation for me to do this thing. [P28]

Participants desired that a mobile app for CR be able to track goals, physical activity, and other health measures such as blood pressure, heart rate, weight, blood glucose, and diet.

Although there were suggestions for additional features to the mobile app, such as the ability to integrate with sensors and automatically transfer data, it was commented that this was not essential.

\section{Memorizing, writing it down and then getting it into your computer, if that was all done while you're doing activities and stuff that would be a big help. But if they can't, this is still a good app. Still helpful. [P28]}

\section{Effort Expectancy}

Several aspects of ease of use of the mobile app emerged. Participants appreciated simplicity.

\section{It was pretty easy...I like that it's simple. [P45]}

The flow is very simple. [P07]

Vision and size of text were cited as a barrier by many participants.
The only downside I see for me is with my vision; the fonts are a little small. I would definitely need to use my reading glasses to read it. [P44]

Prominent display of key features was cited as a facilitator of ease of use.

The settings to change your goals are very easy to reach and very prominent. [P23]

Although some users commented on functions that were not as intuitive and harder to find, it was recognized that with more experience and familiarity, this problem could be overcome.

I'm not used to this. Once I get used to it, I'll know

where everything is. [P40]

One general barrier to ease of use mentioned by participants was the use of passwords and codes. This did not emerge as a barrier specific to our app, but participants were not required to enter a password during the testing session.

\section{Social Influence}

Participants often mentioned a desire to share their data with their providers.

\section{I like the fact that I can put all of that and track it, and that my doctors can as well. I can show my doctor what I've been working on. [P45]}

There was also interest in communicating with providers through the app. Family and peer support were reported to influence mobile technology use. The mobile app does feature a link to an online social networking site for patients with heart disease, but social networking was infrequently mentioned.

\section{Facilitating Conditions}

A desire for hands-on initial training on how to use the mobile app emerged as an important theme. 
Initially, training with a technical person, instead of me relying on myself. [P8]

Expectations for additional help varied, including online, telephone, and family or peer support.

\section{If I had problems I'd try to find out how to fix it on this or call you. [P40]}

But I've got 3 boys that are all pretty much wizards at it, but I'm not. I'm sure I can learn it or if they punch in the application so that it could come right up, I'd be fine. [P19]

\section{Habit}

Habit was frequently mentioned by participants, both with regard to their use of technology and related to participating in physical activity. Habit was also linked by many Veterans to their previous military service. Our interview guides did not specifically probe participants about habit, making the prominent emergence of habit notable. In the discussion of habit, some participants described how memory and learning contribute to the development of habitual use of technology.

Memory appears to play a dual role in use of the technology - in remembering to use the technology and how to use the technology.

Something to remind me. But, I'm going to have to set a schedule of when I actually do this. [P13]

It's a problem with my memory. The program to me seems fine if I can remember how to go through it. [P15]

Learning was discussed often as a period of trial and error where users would become more facile with using the app with greater experience.

Once I learned this app and spent just a little bit of time with it, I'll be good with it. I don't see any problem with it. [P23]

Ultimately, these efforts are expected to result in habitual use of VA FitHeart.

If I were to [use the app] religiously, every day do it, then it'd be force of habit. [P08]

\section{Hedonic Motivation}

Most comments about pleasure derived from using technology were general in nature. Comments about VA FitHeart itself were less strongly pleasurable in nature, but generally positive.

But I like the looks of the app and I like what it's set up to do. [P28]

\section{Price Value}

Though participants mentioned price and cost related to other technologies and mobile apps, price value was infrequently mentioned linked to our mobile app, which will be free for general use.

I think in the end, you could save people, or patients, money. [P35]

\section{Physical Activity}

In our interviews, we identified many of the common barriers and facilitators to physical activity and participation in CR that have been described in previous studies (Multimedia Appendix 5) [34].

Attitudes expressed included general attitudes toward physical activity, as well as comments related to health benefits and the influence of other medical conditions. Many participants commented on subjective norms including the influence of pets, family, and health care providers. Participants frequently mentioned themes relating to perceived behavior control such as goals, habit, motivation, work (as either a facilitator or barrier), and travel or transportation.

We identified one notable emergent theme that does not clearly fall within a single TPB construct and that has not been well described before: the role of military service in physical activity.

\section{Military Service}

Though we specified a priori categories, the topic of military service was mentioned so frequently by our population that we created an emergent category for military service, which may be uniquely important to our patient population. In our population of US military Veterans, almost all Veterans reported their time of military service as a physically active time in life. Their time in military service was often central to their experience related to physical activity.

When I joined the service I was very fit. I usually did physical activity in the morning and sometimes in the afternoon also, an average of 2.5 hours a day, 4 to 5 days a week. [P7]

Additionally, many Veterans described their time after discharge as a particularly inactive time.

I hadn't worked out since the military. It had been like 18 years since I'd set foot in a gym. [P45]

\section{Discussion}

\section{Principal Findings}

We found that iteratively revising a mobile app for CR based on user feedback resulted in significant improvements in the usability of the mobile app. Using a theory-based approach, we revealed interest in using a mobile app to track physical activity and health measures and to share data with providers. Patients expected to have training on how to use the mobile app. On the basis of participant comments, establishing habit, both with regard to physical activity and mobile app use, is anticipated to be a key contributor to adoption of this technology.

This is the first theory-based investigation of the usability of a mobile app for CR. It is known that interventions based on theory are more likely to be effective [20]. Other technology-facilitated interventions for CR have been studied, with promising results $[18,35,36]$. However, these studies did not describe theoretical considerations related to health behaviors or technology use, so we know little about how the interventions influenced patient behavior to achieve their results. Other investigators have also reported the development of 
theory-based mobile CR platforms, but results of their use and efficacy have not been reported [37]. Having a framework for understanding how an intervention produces its effects will be important for studying its impact and adapting interventions beyond research studies. We found that constructs from UTAUT2 [28], especially performance expectancy, effort expectancy, social influence, facilitating conditions, and habit appear to play an important role in use of mobile technology for CR.

Patients in our study desired the ability to track physical activity and health measures with an easy-to-use mobile app, confirming findings from previous studies [18,38,39]. Though some participants expressed a desire for additional features to the mobile app, such as integration with device or peripheral sensors for motion or location, it was commented that these features were not essential. In general, VA FitHeart received praise for its simplicity.

It has previously been reported that people have little desire to share their personal fitness data with their providers [40]. We found that many patients expected to share their data with their health care providers and viewed this as a key advantage to using VA FitHeart. It may be that apps designed to be used for health conditions are viewed differently than consumer personal fitness trackers. Other studies of patient-provider digital communication interventions have demonstrated high levels of satisfaction [41]. Theory related to physical activity behavior and technology use behavior would suggest that sharing data with providers has the potential to influence patient use of a mobile app to promote physical activity through subjective norms and social influence [24,28], and our finding that patients expect to share their data with providers is consistent with this.

Many participants expressed an expectation for in-person training on use of the mobile app, in addition to on-demand help online, via telephone, or from family and friends. Previous studies of older adults have also revealed a preference for in-person training and the influence of family and friends $[42,43]$. It has also been suggested that technology training for older adults may need to be geared toward their needs and learning styles [44,45]. As older adults are less likely to use mobile technology than younger adults, interventions and training geared toward older adults may be necessary [46]. Together, this suggests that interventions for technology-facilitated CR should include opportunities for in-person training of participants on use of the technology, in addition to on-demand help.

Habit was frequently and prominently mentioned by Veterans as a factor that will be important, both for using the mobile app and participating in physical activity. UTAUT2 describes experience and habit as related concepts, with experience being necessary but not sufficient for establishment of habit [28]. In our study, patients frequently discussed memory and learning as prerequisites to habitual use, rather than mentioning experience. For our older population, experience may need to be considered more broadly with regard to repetition and retention of learned behaviors to establish habitual use. In addition, mention of habit was linked by some Veterans to their military service, and it is possible that experience in military service influences how habit is developed in our population. Interestingly, with iterative revisions to improve the usability of the mobile app, we noticed improvements in participant ratings of expected habit and hedonic motivation with use. Though effort expectancy is not theorized to influence habit or hedonic motivation [28], it may be that the usability of a mobile app influences expected adoption of regular use and pleasure derived from the mobile app. Other studies have found that for new users of online fitness communities, self-regulatory motives influence habitual use but that for experienced users, social motives and enjoyment play a larger role [47]. It has also been observed that for social apps, perceived usefulness and hedonic motivation influence habit, which may mediate the effects of perceived usefulness and hedonic motivation on technology use behavior [48]. Together, this suggests that mobile apps that are easier to use may be both more enjoyable to use and more likely to be perceived as habit-forming.

\section{Limitations}

Several limitations to our findings should be considered. We had a small sample size of Veterans and only one female, so our population may not fully represent the population or non-Veteran populations. As not all eligible patients agreed to participate, our findings may not be representative of the entire eligible population. Due to our small sample size, we may not have truly achieved thematic saturation of all factors associated with the use of mobile technology for CR. However, our sample did provide valuable feedback that resulted in improved usability. Additionally, we studied VA FitHeart in a usability testing environment and not in a real-world environment. Further testing is needed in a real-world environment to determine whether other factors are important to use.

\section{Conclusions}

With participant feedback and iterative revisions, we significantly improved the usability of a mobile app for CR. Patient expectations for using a mobile app for CR include tracking health metrics, introductory training, and sharing data with providers. Iterative theory-based mixed-method evaluation may be useful for improving the usability of health technology.

\section{Acknowledgments}

The authors appreciate the support of the Veterans Health Administration Office of Connected Care, Veterans Health Administration National Cardiology Office, Veterans Health Administration Office of Rural Health, and Veterans Affairs Office of Information and Technology in the development of VA FitHeart. 


\section{Conflicts of Interest}

This study was funded by the US Department of Veterans Affairs Virtual Specialty Care Quality Enhancement Research Initiative (QUE 15-282), the Seattle Institute for Biomedical and Clinical Research, the John L. Locke Jr. Charitable Trust, and the Alpha Phi Foundation. ALB is supported by Career Development Award \#16-5150 from the VA Health Services Research and Development Program. The views expressed in this study are those of the authors and do not necessarily reflect the position or policy of the VA or the US Government.

\section{Multimedia Appendix 1}

Mobile Application Use questionnaire.

[PDF File (Adobe PDF File), 33KB-Multimedia Appendix 1]

\section{Multimedia Appendix 2}

Interview guides.

[PDF File (Adobe PDF File), 41KB-Multimedia Appendix 2]

\section{Multimedia Appendix 3}

Screening and enrollment of participants.

[PNG File, 16KB-Multimedia Appendix 3]

\section{Multimedia Appendix 4}

Quotations related to concepts from the extended unified theory of acceptance and use of technology.

[PDF File (Adobe PDF File), 74KB-Multimedia Appendix 4]

\section{Multimedia Appendix 5}

Quotations related to concepts from the Theory of Planned Behavior.

[PDF File (Adobe PDF File), 72KB-Multimedia Appendix 5]

\section{References}

1. Balady GJ, Williams MA, Ades PA, Bittner V, Comoss P, Foody JM, American Heart Association Exercise, Cardiac Rehabilitation, and Prevention Committee, the Council on Clinical Cardiology, American Heart Association Council on Cardiovascular Nursing, American Heart Association Council on Epidemiology and Prevention, American Heart Association Council on Nutrition, Physical Activity, and Metabolism, American Association of Cardiovascular and Pulmonary Rehabilitation. Core components of cardiac rehabilitation/secondary prevention programs: 2007 update: a scientific statement from the American Heart Association Exercise, Cardiac Rehabilitation, and Prevention Committee, the Council on Clinical Cardiology; the Councils on Cardiovascular Nursing, Epidemiology and Prevention, and Nutrition, Physical Activity, and Metabolism; and the American Association of Cardiovascular and Pulmonary Rehabilitation. Circulation 2007 May 22;115(20):2675-2682 [FREE Full text] [doi: 10.1161/CIRCULATIONAHA.106.180945] [Medline: 17513578]

2. Heran BS, Chen JM, Ebrahim S, Moxham T, Oldridge N, Rees K, et al. Exercise-based cardiac rehabilitation for coronary heart disease. Cochrane Database Syst Rev 2011(7):CD001800 [FREE Full text] [doi: 10.1002/14651858.CD001800.pub2] [Medline: 21735386]

3. Wong WP, Feng J, Pwee KH, Lim J. A systematic review of economic evaluations of cardiac rehabilitation. BMC Health Serv Res 2012 Aug 08;12:243 [FREE Full text] [doi: 10.1186/1472-6963-12-243] [Medline: 22873828]

4. Taylor RS, Sagar VA, Davies EJ, Briscoe S, Coats AJ, Dalal H, et al. Exercise-based rehabilitation for heart failure. Cochrane Database Syst Rev 2014(4):CD003331. [doi: 10.1002/14651858.CD003331.pub4] [Medline: 24771460]

5. Beatty AL, Li S, Thomas L, Amsterdam EA, Alexander KP, Whooley MA. Trends in referral to cardiac rehabilitation after myocardial infarction: data from the National Cardiovascular Data Registry 2007 to 2012. J Am Coll Cardiol 2014 Jun 17;63(23):2582-2583 [FREE Full text] [doi: 10.1016/j.jacc.2014.03.030] [Medline: 24768872]

6. Suaya JA, Shepard DS, Normand ST, Ades PA, Prottas J, Stason WB. Use of cardiac rehabilitation by medicare beneficiaries after myocardial infarction or coronary bypass surgery. Circulation 2007 Oct 9;116(15):1653-1662 [FREE Full text] [doi: 10.1161/CIRCULATIONAHA.107.701466] [Medline: 17893274]

7. Schopfer DW, Takemoto S, Allsup K, Helfrich CD, Ho PM, Forman DE, et al. Cardiac rehabilitation use among Veterans with ischemic heart disease. JAMA Intern Med 2014 Oct;174(10):1687-1689. [doi: 10.1001/jamainternmed.2014.3441] [Medline: 25133868] 
8. Daly J, Sindone AP, Thompson DR, Hancock K, Chang E, Davidson P. Barriers to participation in and adherence to cardiac rehabilitation programs: a critical literature review. Prog Cardiovasc Nurs 2002;17(1):8-17. [Medline: 11872976]

9. Jackson L, Leclerc J, Erskine Y, Linden W. Getting the most out of cardiac rehabilitation: a review of referral and adherence predictors. Heart 2005 Jan;91(1):10-14 [FREE Full text] [doi: 10.1136/hrt.2004.045559] [Medline: 15604322]

10. Burns KJ, Camaione DN, Froman RD, Clark BA. Predictors of referral to cardiac rehabilitation and cardiac exercise self-efficacy. Clin Nurs Res 1998 May;7(2):147-163. [doi: 10.1177/105477389800700205] [Medline: 9633337]

11. Smith SCJR, Benjamin EJ, Bonow RO, Braun LT, Creager MA, Franklin BA, World Heart Federation and the Preventive Cardiovascular Nurses Association. AHA/ACCF secondary prevention and risk reduction therapy for patients with coronary and other atherosclerotic vascular disease: 2011 update: a guideline from the American heart association and American college of cardiology foundation. Circulation 2011 Nov 29;124(22):2458-2473 [FREE Full text] [doi: 10.1161/CIR.0b013e318235eb4d] [Medline: 22052934]

12. Taylor RS, Dalal H, Jolly K, Moxham T, Zawada A. Home-based versus centre-based cardiac rehabilitation. Cochrane Database Syst Rev 2010 Jan 20(1):CD007130 [FREE Full text] [doi: 10.1002/14651858.CD007130.pub2] [Medline: 20091618]

13. Balady GJ, Ades PA, Bittner VA, Franklin BA, Gordon NF, Thomas RJ, American Heart Association Science Advisory and Coordinating Committee. Referral, enrollment, and delivery of cardiac rehabilitation/secondary prevention programs at clinical centers and beyond: a presidential advisory from the American Heart Association. Circulation 2011 Dec 20;124(25):2951-2960 [FREE Full text] [doi: 10.1161/CIR.0b013e31823b21e2] [Medline: 22082676]

14. Sandesara PB, Lambert CT, Gordon NF, Fletcher GF, Franklin BA, Wenger NK, et al. Cardiac rehabilitation and risk reduction: time to "rebrand and reinvigorate". J Am Coll Cardiol 2015 Feb 3;65(4):389-395. [doi: 10.1016/j.jacc.2014.10.059] [Medline: 25634839]

15. Fortney JC, Burgess JFJ, Bosworth HB, Booth BM, Kaboli PJ. A re-conceptualization of access for 21st century healthcare. J Gen Intern Med 2011 Nov;26 Suppl 2:639-647 [FREE Full text] [doi: 10.1007/s11606-011-1806-6] [Medline: 21989616]

16. Stephens J, Allen J. Mobile phone interventions to increase physical activity and reduce weight: a systematic review. J Cardiovasc Nurs 2013;28(4):320-329 [FREE Full text] [doi: 10.1097/JCN.0b013e318250a3e7] [Medline: 22635061]

17. Devi R, Singh SJ, Powell J, Fulton EA, Igbinedion E, Rees K. Internet-based interventions for the secondary prevention of coronary heart disease. Cochrane Database Syst Rev 2015(12):CD009386. [doi: 10.1002/14651858.CD009386.pub2] [Medline: 26691216]

18. Beatty AL, Fukuoka Y, Whooley MA. Using mobile technology for cardiac rehabilitation: a review and framework for development and evaluation. J Am Heart Assoc 2013;2(6):e000568 [FREE Full text] [doi: 10.1161/JAHA.113.000568] [Medline: 24185949]

19. Park LG, Beatty A, Stafford Z, Whooley MA. Mobile phone interventions for the secondary prevention of cardiovascular disease. Prog Cardiovasc Dis 2016;58(6):639-650. [doi: 10.1016/j.pcad.2016.03.002] [Medline: 27001245]

20. Glanz K, Bishop DB. The role of behavioral science theory in development and implementation of public health interventions. Annu Rev Public Health 2010;31:399-418. [doi: 10.1146/annurev.publhealth.012809.103604] [Medline: 20070207]

21. Breton ER, Fuemmeler BF, Abroms LC. Weight loss-there is an app for that! But does it adhere to evidence-informed practices? Transl Behav Med 2011 Dec;1(4):523-529 [FREE Full text] [doi: 10.1007/s13142-011-0076-5] [Medline: 24073074]

22. Nilsen W, Kumar S, Shar A, Varoquiers C, Wiley T, Riley WT, et al. Advancing the science of mHealth. J Health Commun 2012;17 Suppl 1:5-10. [doi: 10.1080/10810730.2012.677394] [Medline: 22548593]

23. Riley WT, Rivera DE, Atienza AA, Nilsen W, Allison SM, Mermelstein R. Health behavior models in the age of mobile interventions: are our theories up to the task? Transl Behav Med 2011 Mar;1(1):53-71 [FREE Full text] [doi: 10.1007/s13142-011-0021-7] [Medline: 21796270]

24. Ajzen I. The theory of planned behavior. Organ Behav Hum Decis Process 1991 Dec;50(2):179-211. [doi: 10.1016/0749-5978(91)90020-T]

25. Blanchard CM, Courneya KS, Rodgers WM, Fraser SN, Murray TC, Daub B, et al. Is the theory of planned behavior a useful framework for understanding exercise adherence during phase II cardiac rehabilitation? J Cardiopulm Rehabil 2003;23(1):29-39. [Medline: 12576910]

26. Blanchard CM, Reid RD, Morrin LI, McDonnell L, McGannon K, Rhodes RE, et al. Understanding physical activity during home-based cardiac rehabilitation from multiple theoretical perspectives. J Cardiopulm Rehabil Prev 2011;31(3):173-180. [doi: 10.1097/HCR.0b013e3181ff0dfe] [Medline: 21796061]

27. Venkatesh V, Morris MG, Davis FD, Davis GB. User acceptance of information technology: toward a unified view. MIS Q 2003:425-478. [doi: $10.2307 / 30036540$ ]

28. Venkatesh $\mathrm{V}$, Thong $\mathrm{J}, \mathrm{Xu}$ X. Consumer acceptance and use of information technology: extending the unified theory of acceptance and use of technology. MIS Q 2012:157-178.

29. Harris PA, Taylor R, Thielke R, Payne J, Gonzalez N, Conde JG. Research electronic data capture (REDCap)--a metadata-driven methodology and workflow process for providing translational research informatics support. J Biomed Inform 2009 Apr;42(2):377-381 [FREE Full text] [doi: 10.1016/j.jbi.2008.08.010] [Medline: 18929686] 
30. Bangor A, Kortum PT, Miller JT. An empirical evaluation of the system usability scale. Int J Hum Comput Interact 2008 Jul 30;24(6):574-594. [doi: 10.1080/10447310802205776]

31. Sauro J. MeasuringU. Measuring usability with the system usability scale (SUS) URL: https://measuringu.com/sus/[WebCite Cache ID 6qMTVO9ya]

32. Elo S, Kyngäs H. The qualitative content analysis process. J Adv Nurs 2008 Apr;62(1):107-115. [doi: 10.1111/j.1365-2648.2007.04569.x] [Medline: 18352969]

33. Eysenbach G, CONSORT-EHEALTH Group. CONSORT-EHEALTH: improving and standardizing evaluation reports of web-based and mobile health interventions. J Med Internet Res 2011 Dec 31;13(4):e126 [FREE Full text] [doi: 10.2196/jmir.1923] [Medline: 22209829]

34. Neubeck L, Freedman SB, Clark AM, Briffa T, Bauman A, Redfern J. Participating in cardiac rehabilitation: a systematic review and meta-synthesis of qualitative data. Eur J Prev Cardiol 2012 Jun;19(3):494-503. [Medline: 22779092]

35. Varnfield M, Karunanithi M, Lee C, Honeyman E, Arnold D, Ding H, et al. Smartphone-based home care model improved use of cardiac rehabilitation in postmyocardial infarction patients: results from a randomised controlled trial. Heart 2014 Nov;100(22):1770-1779 [FREE Full text] [doi: 10.1136/heartjnl-2014-305783] [Medline: 24973083]

36. Widmer RJ, Allison TG, Lennon R, Lopez-Jimenez F, Lerman LO, Lerman A. Digital health intervention during cardiac rehabilitation: a randomized controlled trial. Am Heart J 2017 Feb 20;188:65-72. [doi: 10.1016/j.ahj.2017.02.016] [Medline: 28577682]

37. Rawstorn JC, Gant N, Meads A, Warren I, Maddison R. Remotely delivered exercise-based cardiac rehabilitation: design and content development of a novel mhealth platform. JMIR Mhealth Uhealth 2016;4(2):e57 [FREE Full text] [doi: 10.2196/mhealth.5501] [Medline: 27342791]

38. Pfaeffli L, Maddison R, Whittaker R, Stewart R, Kerr A, Jiang Y, et al. A mHealth cardiac rehabilitation exercise intervention: findings from content development studies. BMC Cardiovasc Disord 2012;12:36 [FREE Full text] [doi:

10.1186/1471-2261-12-36] [Medline: 22646848]

39. Rabin C, Bock B. Desired features of smartphone applications promoting physical activity. Telemed J E Health 2011 Dec;17(10):801-803. [doi: 10.1089/tmj.2011.0055] [Medline: 22010977]

40. Pevnick JM, Fuller G, Duncan R, Spiegel BM. A large-scale initiative inviting patients to share personal fitness tracker data with their providers: initial results. PLoS One 2016;11(11):e0165908 [FREE Full text] [doi: 10.1371/journal.pone.0165908] [Medline: 27846287]

41. Gordon CR, Rezzadeh KS, Li A, Vardanian A, Zelken J, Shores JT, et al. Digital mobile technology facilitates HIPAA-sensitive perioperative messaging, improves physician-patient communication, and streamlines patient care. Patient Saf Surg 2015;9:21 [FREE Full text] [doi: 10.1186/s13037-015-0070-9] [Medline: 26136830]

42. Nguyen T, Irizarry C, Garrett R, Downing A. Access to mobile communications by older people. Australas J Ageing 2015 Jun;34(2):E7-E12. [doi: 10.1111/ajag.12149] [Medline: 24750499]

43. Cook N, Winkler SL. Acceptance, usability and health applications of virtual worlds by older adults: a feasibility study. JMIR Res Protoc 2016 Jun 02;5(2):e81 [FREE Full text] [doi: 10.2196/resprot.5423] [Medline: 27256457]

44. Hickman JM, Rogers WA, Fisk AD. Training older adults to use new technology. J Gerontol B Psychol Sci Soc Sci 2007 Jun;62 Spec No 1:77-84. [Medline: 17565168]

45. Williams K, Pennathur P, Bossen A, Gloeckner A. Adapting telemonitoring technology use for older adults: a pilot study. Res Gerontol Nurs 2016;9(1):17-23 [FREE Full text] [doi: 10.3928/19404921-20150522-01] [Medline: 26020575]

46. Gallagher R, Roach K, Sadler L, Glinatsis H, Belshaw J, Kirkness A, et al. Mobile technology use across age groups in patients eligible for cardiac rehabilitation: survey study. JMIR Mhealth Uhealth 2017 Oct 24;5(10):e161 [FREE Full text] [doi: 10.2196/mhealth.8352] [Medline: 29066425]

47. Stragier J, Vanden Abeele M, Mechant P, De Marez L. Understanding persistence in the use of online fitness communities: comparing novice and experienced users. Comput Human Behav 2016 Nov;64:34-42. [doi: 10.1016/j.chb.2016.06.013]

48. Hsiao C, Chang J, Tang K. Exploring the influential factors in continuance usage of mobile social apps: Satisfaction, habit, and customer value perspectives. Telemat Inform 2016 May;33(2):342-355. [doi: 10.1016/j.tele.2015.08.014]

\section{Abbreviations}

CR: cardiac rehabilitation

SUS: System Usability Scale

TPB: Theory of Planned Behavior

UTAUT: Unified Theory of Acceptance and Use of Technology

UTAUT2: Unified Theory of Acceptance and Use of Technology extension for consumer use of technology

VA: Veterans Affairs 
Edited by G Eysenbach; submitted 12.05.17; peer-reviewed by M Varnfield, J Redfern; comments to author 10.10.17; revised version received 28.11.17; accepted 30.11.17; published 15.01 .18

Please cite as:

Beatty AL, Magnusson SL, Fortney JC, Sayre GG, Whooley MA

VA FitHeart, a Mobile App for Cardiac Rehabilitation: Usability Study

JMIR Hum Factors 2018;5(1):e3

URL: http://humanfactors.jmir.org/2018/1/e3/

doi: 10.2196/humanfactors.8017

PMID: 29335235

(CAlexis L Beatty, Sara L Magnusson, John C Fortney, George G Sayre, Mary A Whooley. Originally published in JMIR Human Factors (http://humanfactors.jmir.org), 15.01.2018. This is an open-access article distributed under the terms of the Creative Commons Attribution License (https://creativecommons.org/licenses/by/4.0/), which permits unrestricted use, distribution, and reproduction in any medium, provided the original work, first published in JMIR Human Factors, is properly cited. The complete bibliographic information, a link to the original publication on http://humanfactors.jmir.org, as well as this copyright and license information must be included. 